\title{
Optogenetics Applications for Treating Spinal Cord Injury
}

\author{
Aftab Ahmad ${ }^{1}$, Sadia Ashraf ${ }^{2}$, Shoji Komai ${ }^{1}$ \\ ${ }^{1}$ Graduate School of Biological Sciences, Nara Institute of Science and Technology, Ikoma, Nara, Japan \\ ${ }^{2}$ Department of Biology, Lahore University of Management Sciences (LUMS), Lahore, Pakistan
}

Cases of spinal cord injury (SCI) are increasing all over the world; and in USA alone, there are 273,000 patients, which not only leads to morbidity and mortality but also results in a great economic burden. Many approaches are being used at the pre-clinical and clinical level to treat SCI including therapeutic agents, surgical decompression, stem cell therapy etc. Recently, a new approach called optogenetics has emerged in which light sensitive proteins are used to switch neurons on and off, and this approach has great potential to be used as therapy due to its specificity and rapid response in milliseconds. Few animal studies have been performed so far in which the respiratory and bladder function of rats was restored through the use of optogenetics. On the basis of promising results obtained, in the future, this approach can prove to be a valuable tool to treat patients with SCl.

Keywords: Optogenetics; Spinal cord injury; Photostimulation; Stem cells; Regeneration

\section{Introduction}

Optogenetics is a recently introduced approach to control the activity of cells through the use of light stimulation at a particular wavelength. This manipulation of activity of cells can be done both in vitro and in vivo with high precision. In this technique, individual cells can be targeted and their activity can be switched on and off by light on a timescale of milliseconds, and this makes it unique. The approach is very precise and it also has a quick action than the available drugs, although some molecular manipulations would be needed in advance. This technology is very amazing and it has enormous potential and that's why the prestigious "Nature Journal" declared optogenetics as the "method of the year" in 2010. In addition the "Science Magazine" also declared optogenetics as the "breakthrough of the last decade" [1].

The pioneer work in this field was done by Deisseroth et al. [2] and Boyden et al. [3] of Stanford University. They made neuronal cells light sensitive by applying a light sensitive protein isolated from Chlamydomonas reinhardtii. The same team coined the term "optogenetics". After this pioneering work, there has been an explosion in optogenetics research all around the world.

The earlier work in the field of optogenetics was performed in cell culture; but with the advent and application of fiber optics, some trials with living animals have been initiated, and this is how in vivo optogenetic experimental work started. Therefore, with an increase in the optogenetics toolkit, its application to study neural circuits, neurological diseases, neuronal stem cells, and non-neuronal cells has enhanced $[4,5]$.

Received Oct 21, 2014; Revised Nov 8, 2014; Accepted Nov 16, 2014

Corresponding author: Aftab Ahmad

Graduate School of Biological Sciences, Nara Institute of Science and Technology,

8916-5 Takayama, Ikoma, Nara 630-0192 Japan

Tel: +81-743-72-5418, Fax: +81-743-72-5419, E-mail: aftabac@yahoo.com 


\section{Spinal Cord Injury}

According to World Health Organization, the term 'spinal cord injury' (SCI) refers to "damage to the spinal cord resulting from trauma or from disease or degeneration". Due to lack of data, especially from the developing countries, there is no reliable estimate of global prevalence of SCI; but according to an estimate there are $40-80$ cases of SCI per million population. In USA alone, there are 273,000 patients of SCI. Majority of the cases are due to trauma, while the cases of non-traumatic injury are also increasing [6]. Most of the individuals who sustain a SCI die before reaching the hospital, and those who survive face high risk of morbidity and mortality. In addition, the economic costs related to SCI are in billions of dollars in developed countries and they are also a great economic burden in developing countries. Among all the age groups, mostly young people sustain a traumatic SCI, and in all the cases, it not only results in economic loss but also in great personal and family suffering $[7,8]$.

\section{Current Treatment Strategies}

SCI occurs at different locations of the spinal cord, and the intensity and degree of the damage varies from patient to patient. The following is the list of available treatment options for SCI patients (Fig. 1); but a few of these treatments have been tested in animal models and no human trials have been performed so far.

\section{Therapeutic agents}

More facts and knowledge of SCI and pathological data of the disease have been accumulated as compared to the past; therefore, many new therapeutic agents are in clinical trials and they offer the possibility of being used as therapy. Among these different therapeutic agents, neuroprotective agents are the main focus of researchers. One of the neuro-protective agents is riluzole, which is currently in use to treat amyotrophic lateral sclerosis patients. It has received special attention and many pre-clinical studies have been performed. It blocks voltage sensitive sodium channels and also inhibits presynaptic calcium dependent glutamate release. Most of these studies were performed in a rat model of SCI and rats showed improvement in electro-physiological activities, better locomotor scores, and better performance in the inclined plane test. After treatment with riluzole, the number of neurons at the injury site was reported to be increased. Kitzman [9] also reported transient improvement in plasticity [10-14].

\section{Rho antagonists}

Rho is a signaling molecule which acts as an inhibitor of the regeneration process; therefore, scientists also focused on the inhibitor of Rho to block its signaling. When surgery for SCI is performed, Rho inhibitors are applied directly under the dura mater. So far, many preclinical trials of Rho antagonists have been performed. The compounds not only caused an improvement in histological, biochemical, and physiological functions, but also in behavioral function of the mice and rats as shown in locomotor activity. Most of the studies concluded that there was reduction in lesions after the antagonist treatment and only a single study did not show an effect on the regeneration process [15-22].

\section{Surgical decompression}

Surgical decompression is another treatment of SCI, in which surgery is performed and the spinal cord is compressed with a fixed duration of time. Many pre-clinical and clinical trials have shown improved neurological outcome after early decompression. In this case, early surgery is required which is usually performed within 24 hours of injury. In different studies, the degree and length of compression were studied and they were correlated with the degree of recovery. There are also some negative consequences in the form of direct damage to the neural

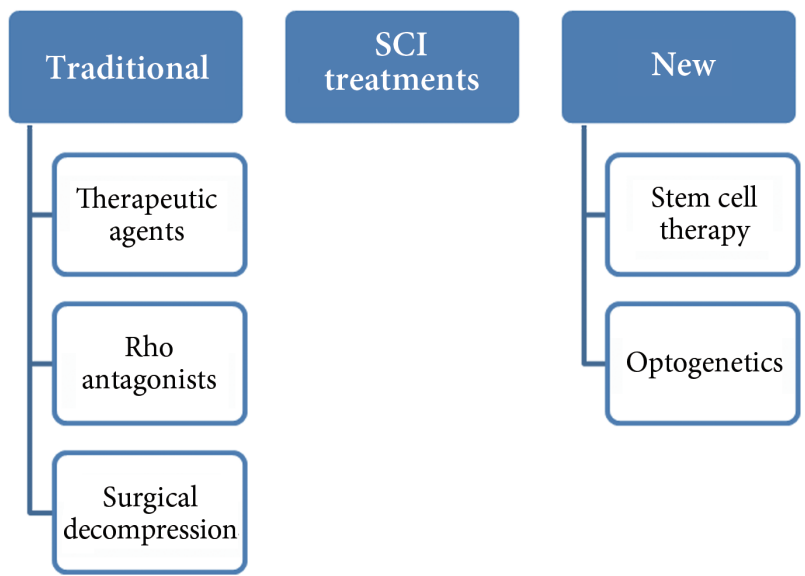

Fig. 1. A simplified chart of different SCI treatment options including the traditional and new options. SCl, spinal cord injury. 
cell membrane by applying direct pressure after SCI and it can lead to loss of neurological function [23-26].

According to some animal studies, if less force is applied and the duration is short, animals showed improvement after SCI and better behavioral outcome $[27,28]$.

\section{Stem cell therapy}

It is very difficult to restore the normal function after SCI by using conventional approaches as addition of new functional cells at the site of injury is needed to compensate for the loss of cells. Recently, stem cells have also been considered to be a potential therapy for SCI. After $\mathrm{SCI}$, the endogenous regenerative system becomes active and attempts to repair the injury, especially Schwann cells, which promote regeneration, move towards the injury site, and myelinate spinal cord exons. In addition, the genes which are involved in the regeneration process also become active at the site of injury [29-31]. Some investigators have also shown that there is proliferation of local stem cells but their growth is inhibited by release of inhibitors of scar tissue formation. In addition, there is also a problem that the stem cells do not integrate functionally into the spinal cord tissue at the site of injury [32-34]. Stem cells and neuronal progenitor cells can be used to repair SCI as these cells can become neural cells and can support not only anatomical but also functional recovery. In addition, they also secrete growth factors and neuro-protective factors that not only promote axon regeneration and formation of new connections, but also protect the neurons from further injury. So far, many studies have been performed to assess the effect of stem cells on SCI repair and the short-comings of the methods have also been investigated in detail [35-38]. In a study by Abematsu et al. [39], they used neural stem cells (NSCs) for the treatment of SCI together with the administration of valproic acid and this combination dra- matically enhanced the restoration of hind limb function in the mouse model. The study also demonstrated that the transplanted NSCs reconstructed broken neuronal circuits and contributed to restoration of motor function [39]. According to different pre-clinical and clinical trials, stem cell therapy is a promising approach to treat SCI [37].

\section{Optogenetics}

In addition to stem cell therapy, it is necessary to make the transplanted cells work together with endogenous neurons to rebuild the functional network, and optogenetics can play a vital role in reconstruction of broken neuronal circuits.

By the expression of algal protein (channelrhodopsin-2, ChR2), which is a light activated cation channel protein the action potential can be generated in neurons [40]. According to some of the studies performed on nematodes, their swimming behavior can be changed by expression of a light sensitive protein and on exposure to light, in the same way these light sensitive channels can be expressed in mammalian neurons and functional activity of the neurons can be changed [41-43].

One potential application of these light switches is in the treatment of neurological disorders including traumatic brain and SCI. As we have previously mentioned that after SCI, the motor neurons are disrupted and there is a loss of motor function of the body. In this condition, the light sensitive protein can be expressed in motor neurons and they can be activated by a specific wavelength of light; otherwise, they remain dormant because of lack of regeneration and are also unable to develop connections with other neurons on the other side of injury [44]. In the following sections, we will provide some specific examples of application of optogenetics in cases of SCI. A simplified working model for optogenetics is shown in Fig. 2.

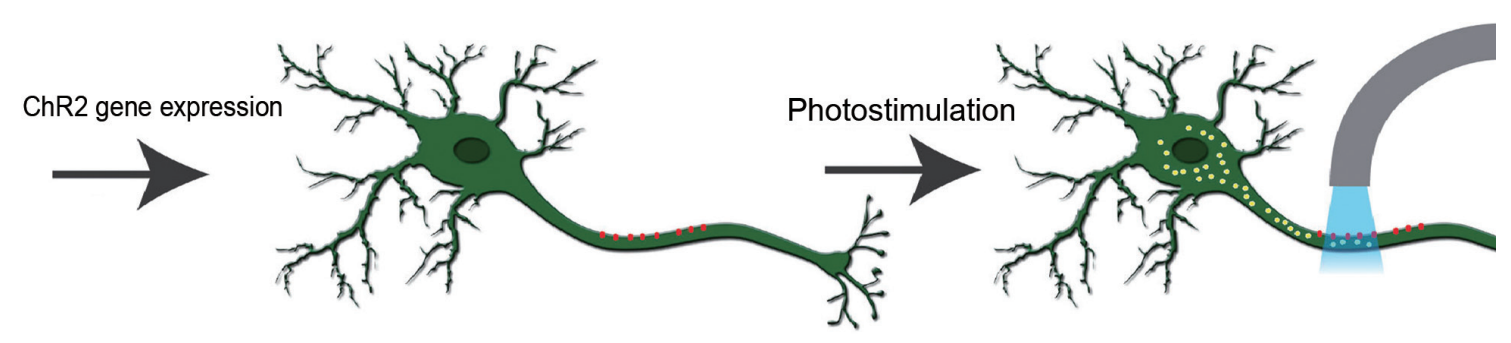

Fig. 2. Optogenetics working model. Initially, channelrhodopsin (ChR2) gene is expressed in neurons and then the ChR2 gene is activated by a specific wavelength of light which stimulates the neurons. 
1) Restoration of respiration function after SCI

Among SCI, the injuries at the cervical level are the most common and often result in severe respiratory problems as there is an interruption of the descending bulbospinal inputs to the ipsilateral phrenic nucleus which normally results in unilateral paralysis [45]. The electromyographic activity can be restored by the crossed phrenic pathway; but this can be stressful to the animal and also the activity is partially restored $[45,46]$. The advantage of optogenetics technique is that it is relatively less invasive and also has powerful stimulating effects on the central nervous system (CNS). In a study performed by Alilain et al. [47], they introduced the Sindbis viral vector containing ChR2 gene into the gray matter of the spinal cord after a SCI in the $\mathrm{C} 2$ region. The results clearly indicated that there was expression of ChR2 in both spinal motor neurons and interneurons, and on activation of $\mathrm{ChR} 2$ by light, there was recovery of muscle activity and restoration of respiratory activity in injured rats [4].

\section{2) Lower body functions}

SCI results in the loss of locomotor, bowel, bladder, and sexual functions, and it becomes difficult to restore all of these functions. The patients have to use adoptive strategies such as the use of wheel chair or urinary catheter throughout their remaining life. In an optogenetics study of SCI, ChR2, and halorhodopsin (NpHR) genes were introduced into the spinal cord of rats before SCI and it was expected that light activation could restore normal bladder function after injury [48]. Both ChR2 and NpHR genes were introduced into the adult male spinal cord by lentiviral vectors followed by SCI at the T8 region. After the injury, the lost bladder function was restored by light stimulation. In conclusion, the targeting of motor neurons in the spinal cord with optogenetics tools resulted in induction of recovery of urinary function after experimentally induced SCI in rats, and on the basis of these promising results, this technology can be translated and used in humans to restore the bladder and other body functions after SCI [48].

\section{3) Control of muscle function}

After SCI, there is loss of connection between the motor and sensory axons of the central and peripheral nervous system (PNS). If there is electrical stimulation of motor axons in the PNS, it results in induction of muscle contraction as phrenic nerve pacing is currently used to control the function of the diaphragm [49]. But, as the peripheral nerves are composed of different sensory and motor axons, functional electrical stimulation not only stimulates the nerves indiscriminately but also causes considerable discomfort; therefore, more specific activation of nerves is needed [50].

Recently, it has been observed that motor neurons from embryonic stem cells (ESCs) can be engrafted into the PNS and these neurons can also be activated but they do not connect with the CNS due to SCI or other traumatic injury of the nervous system; hence, these nerves cannot receive descending inputs from the brain. In addition, on electrical stimulation of these neurons, endogenous neurons also get activated due to the lack of specificity [49]. As the optogenetic approach is very specific, the optogenetics technology is the solution to this problem and other similar problems as according to a study when the ChR2 gene was expressed in endogenous motor neurons of mice, the axons of these motor neurons were excited by optical stimulation in a graded fashion and this resulted in optogenetic control of muscle function [51]. In another study, the ChR2 gene was expressed in motor neurons of adult rats and it resulted in generation of action potential on light stimulation and hence restoration of muscle function [52].

According to a recent study by Bryson et al. [50], motor neurons were generated from ESCs that express the ChR2 gene and were engrafted into partially denervated branches of the sciatic nerve of mice. In the first step, these engrafted motor neurons reinnervated muscles and on optogenetic stimulation, they restored the function of muscle in a controlled and specific way. Therefore according to this study, optogenetics and regenerative medicine could be very helpful in restoration of normal muscle function after SCI or other traumatic brain injuries [50].

\section{Future Perspective}

With the current understanding of neuroscience at the molecular level and emergence of new tools in the form of light sensitive proteins, there is a good chance to understand and treat different neurological disorders like epilepsy, Parkinson's disease, and SCI. The motor and interneurons can be targeted and light sensitive protein can be expressed in these neurons, as proved by different studies, to restore the function of neurons and also to enhance their plasticity and connectivity. In addition 
with the optogenetics toolkit and the expression of specific gene under neuron specific promoters, the exact function of different neurons can be studied in detail and hence better treatment can be provided after different spinal cord diseases. So far, there are fewer studies on the use of optogenetics for treating SCI; but on the basis of results of recently performed studies, it can be speculated that the technology has great potential, especially for the restoration of lower body functions (bowel, bladder, and sexual functions). However, to reach the therapy stage a lot more investigations and animal models are needed so that the therapy could be specifically tailored according to the requirement of SCI patients. On the basis of successful results, more studies should be performed in higher primates as they are genetically closer to humans so that the success rate of this technology could be measured and finally it could be used in human trials.

\section{Conclusions}

Optogenetics is a new scientific approach that can stimulate neuronal cells in milliseconds with great precision, which has paved the way for its enormous number of applications in areas of basic and applied neurosciences. Although there are very few studies on application of optogenetics in SCI using animal models, the results have provided great hope for the use of this technology in humans. In future, optogenetics could be a valuable tool for the treatment of patients with SCI.

\section{Conflict of Interest}

No potential conflict of interest relevant to this article was reported.

\section{References}

1. Lyon L. Optogenetics. Mater Methods 2013;3:194.

2. Deisseroth K, Feng G, Majewska AK, Miesenbock G, Ting A, Schnitzer MJ. Next-generation optical technologies for illuminating genetically targeted brain circuits. J Neurosci 2006;26:10380-6.

3. Boyden ES, Zhang F, Bamberg E, Nagel G, Deisseroth K. Millisecond-timescale, genetically targeted optical control of neural activity. Nat Neurosci 2005;8:12638.

4. Adamantidis AR, Zhang F, Aravanis AM, Deisseroth
K, de Lecea L. Neural substrates of awakening probed with optogenetic control of hypocretin neurons. Nature 2007;450:420-4.

5. Aravanis AM, Wang LP, Zhang F, et al. An optical neural interface: in vivo control of rodent motor cortex with integrated fiberoptic and optogenetic technology. J Neural Eng 2007;4:S143-56.

6. World Health Organization (WHO). Spinal cord injury: fact sheets [Internet]. Geneva: WHO; 2013 [cited 2014 Oct 15]. Available from: http://www.who. int/mediacentre/ factsheets/fs384/en/.

7. Cadotte DW, Fehlings MG. Spinal cord injury: a systematic review of current treatment options. Clin Orthop Relat Res 2011;469:732-41.

8. Harvey C, Wilson SE, Greene CG, Berkowitz M, Stripling TE. New estimates of the direct costs of traumatic spinal cord injuries: results of a nationwide survey. Paraplegia 1992;30:834-50.

9. Kitzman PH. Effectiveness of riluzole in suppressing spasticity in the spinal cord injured rat. Neurosci Lett 2009;455:150-3.

10. Ates O, Cayli SR, Gurses I, et al. Comparative neuroprotective effect of sodium channel blockers after experimental spinal cord injury. J Clin Neurosci 2007; 14:658-65.

11. $\mathrm{Mu} \mathrm{X}$, Azbill RD, Springer JE. Riluzole improves measures of oxidative stress following traumatic spinal cord injury. Brain Res 2000;870:66-72.

12. Schwartz G, Fehlings MG. Evaluation of the neuroprotective effects of sodium channel blockers after spinal cord injury: improved behavioral and neuroanatomical recovery with riluzole. J Neurosurg 2001; 94:245-56.

13. Springer JE, Azbill RD, Kennedy SE, George J, Geddes JW. Rapid calpain I activation and cytoskeletal protein degradation following traumatic spinal cord injury: attenuation with riluzole pretreatment. J Neurochem 1997;69:1592-600.

14. Stutzmann JM, Pratt J, Boraud T, Gross C. The effect of riluzole on post-traumatic spinal cord injury in the rat. Neuroreport 1996;7:387-92.

15. Chan CC, Khodarahmi K, Liu J, et al. Dose-dependent beneficial and detrimental effects of ROCK inhibitor Y27632 on axonal sprouting and functional recovery after rat spinal cord injury. Exp Neurol 2005;196:352-64.

16. Dergham P, Ellezam B, Essagian C, Avedissian H, 
Lubell WD, McKerracher L. Rho signaling pathway targeted to promote spinal cord repair. J Neurosci 2002;22:6570-7.

17. Dubreuil CI, Winton MJ, McKerracher L. Rho activation patterns after spinal cord injury and the role of activated Rho in apoptosis in the central nervous system. J Cell Biol 2003;162:233-43.

18. Fournier AE, Takizawa BT, Strittmatter SM. Rho kinase inhibition enhances axonal regeneration in the injured CNS. J Neurosci 2003;23:1416-23.

19. Lord-Fontaine S, Yang F, Diep Q, et al. Local inhibition of Rho signaling by cell-permeable recombinant protein BA-210 prevents secondary damage and promotes functional recovery following acute spinal cord injury. J Neurotrauma 2008;25:1309-22.

20. Nishio Y, Koda M, Kitajo K, et al. Delayed treatment with Rho-kinase inhibitor does not enhance axonal regeneration or functional recovery after spinal cord injury in rats. Exp Neurol 2006;200:392-7.

21. Sung JK, Miao L, Calvert JW, Huang L, Louis Harkey $\mathrm{H}$, Zhang JH. A possible role of RhoA/Rho-kinase in experimental spinal cord injury in rat. Brain Res 2003;959:29-38.

22. Tanaka H, Yamashita T, Yachi K, Fujiwara T, Yoshikawa H, Tohyama M. Cytoplasmic p21(Cip1/WAF1) enhances axonal regeneration and functional recovery after spinal cord injury in rats. Neuroscience 2004;127:155-64.

23. Aki T, Toya S. Experimental study on changes of the spinal-evoked potential and circulatory dynamics following spinal cord compression and decompression. Spine (Phila Pa 1976) 1984;9:800-9.

24. Bohlman HH, Bahniuk E, Raskulinecz G, Field G. Mechanical factors affecting recovery from incomplete cervical spinal cord injury: a preliminary report. Johns Hopkins Med J 1979;145:115-25.

25. Brodkey JS, Richards DE, Blasingame JP, Nulsen FE. Reversible spinal cord trauma in cats. Additive effects of direct pressure and ischemia. J Neurosurg 1972;37: 591-3.

26. Kobrine AI, Evans DE, Rizzoli H. Correlation of spinal cord blood flow and function in experimental compression. Surg Neurol 1978;10:54-9.

27. Dolan EJ, Tator CH, Endrenyi L. The value of decompression for acute experimental spinal cord compression injury. J Neurosurg 1980;53:749-55.

28. Guha A, Tator CH, Endrenyi L, Piper I. Decompres- sion of the spinal cord improves recovery after acute experimental spinal cord compression injury. Paraplegia 1987;25:324-39.

29. Franklin RJ, Blakemore WF. Requirements for Schwann cell migration within CNS environments: a viewpoint. Int J Dev Neurosci 1993;11:641-9.

30. Gardiner P, Beaumont E, Cormery B. Motoneurones "learn" and "forget" physical activity. Can J Appl Physiol 2005;30:352-70.

31. Takami T, Oudega M, Bates ML, Wood PM, Kleitman N, Bunge MB. Schwann cell but not olfactory ensheathing glia transplants improve hindlimb locomotor performance in the moderately contused adult rat thoracic spinal cord. J Neurosci 2002;22:6670-81.

32. Ke Y, Chi L, Xu R, Luo C, Gozal D, Liu R. Early response of endogenous adult neural progenitor cells to acute spinal cord injury in mice. Stem Cells 2006;24: 1011-9.

33. Martens DJ, Seaberg RM, van der Kooy D. In vivo infusions of exogenous growth factors into the fourth ventricle of the adult mouse brain increase the proliferation of neural progenitors around the fourth ventricle and the central canal of the spinal cord. Eur J Neurosci 2002;16:1045-57.

34. Tian DS, Dong Q, Pan DJ, et al. Attenuation of astrogliosis by suppressing of microglial proliferation with the cell cycle inhibitor olomoucine in rat spinal cord injury model. Brain Res 2007;1154:206-14.

35. Chen CP, Kiel ME, Sadowski D, McKinnon RD. From stem cells to oligodendrocytes: prospects for brain therapy. Stem Cell Rev 2007;3:280-8.

36. Hardy SA, Maltman DJ, Przyborski SA. Mesenchymal stem cells as mediators of neural differentiation. Curr Stem Cell Res Ther 2008;3:43-52.

37. Nandoe Tewarie RS, Hurtado A, Bartels RH, Grotenhuis A, Oudega M. Stem cell-based therapies for spinal cord injury. J Spinal Cord Med 2009;32:105-14

38. Zietlow R, Lane EL, Dunnett SB, Rosser AE. Human stem cells for CNS repair. Cell Tissue Res 2008;331: 301-22.

39. Abematsu M, Tsujimura K, Yamano M, et al. Neurons derived from transplanted neural stem cells restore disrupted neuronal circuitry in a mouse model of spinal cord injury. J Clin Invest 2010;120:3255-66.

40. Herlitze S, Landmesser LT. New optical tools for controlling neuronal activity. Curr Opin Neurobiol 2007;17:87-94. 
41. Lagali PS, Balya D, Awatramani GB, et al. Light-activated channels targeted to $\mathrm{ON}$ bipolar cells restore visual function in retinal degeneration. Nat Neurosci 2008;11:667-75.

42. Li X, Gutierrez DV, Hanson MG, et al. Fast noninvasive activation and inhibition of neural and network activity by vertebrate rhodopsin and green algae channelrhodopsin. Proc Natl Acad Sci U S A 2005; 102:17816-21.

43. Sacre Hazouri JA, de la Torre Gonzalez C, Lopez Gonzalez AL, Alvarez Vega R. Intrasal corticosteriods prescription to allergic rhinoconjunctivitis and rhinosinusitis during pediatric ages. Rev Alerg Mex 2007;54:205-12.

44. Houle JD, Tom VJ, Mayes D, Wagoner G, Phillips $\mathrm{N}$, Silver J. Combining an autologous peripheral nervous system "bridge" and matrix modification by chondroitinase allows robust, functional regeneration beyond a hemisection lesion of the adult rat spinal cord. J Neurosci 2006;26:7405-15.

45. Zimmer MB, Nantwi K, Goshgarian HG. Effect of spinal cord injury on the respiratory system: basic research and current clinical treatment options. J Spinal Cord Med 2007;30:319-30.

46. Fuller DD, Johnson SM, Olson EB Jr, Mitchell GS. Synaptic pathways to phrenic motoneurons are en- hanced by chronic intermittent hypoxia after cervical spinal cord injury. J Neurosci 2003;23:2993-3000.

47. Alilain WJ, Li X, Horn KP, et al. Light-induced rescue of breathing after spinal cord injury. J Neurosci 2008; 28:11862-70.

48. Awad BI, Gutierrez DV, Alilain W, Steinmetz MP. Optogenetic photostimulation to control bladder function after experimental spinal cord injury. Spine J 2013;13:S12.

49. Onders RP, Elmo M, Khansarinia S, et al. Complete worldwide operative experience in laparoscopic diaphragm pacing: results and differences in spinal cord injured patients and amyotrophic lateral sclerosis patients. Surg Endosc 2009;23:1433-40.

50. Bryson JB, Machado CB, Crossley M, et al. Optical control of muscle function by transplantation of stem cell-derived motor neurons in mice. Science 2014; 344:94-7.

51. Towne C, Montgomery KL, Iyer SM, Deisseroth K, Delp SL. Optogenetic control of targeted peripheral axons in freely moving animals. PLoS One 2013;8: e72691.

52. Yohn DC, Miles GB, Rafuse VF, Brownstone RM. Transplanted mouse embryonic stem-cell-derived motoneurons form functional motor units and reduce muscle atrophy. J Neurosci 2008;28:12409-18. 